\title{
Increasing the Structural Strength of Corrosion-resistant Steel for Elastic Compo- nents of Diaphragm Compressor
}

Jan Krmela ${ }^{1,2}$, Tetiana Hovorun ${ }^{3}$, Kristina Berladir ${ }^{3}$, Artem Artyukhov ${ }^{4}$

${ }^{1}$ Faculty of Mechanical Engineering, J. E. Purkyně University in Ustí nad Labem. Pasteurova 3334/7, 40001 Ustí nad Labem. Czech Republic. E-mail: jan.krmela@ujep.cz

${ }^{2}$ Faculty of Industrial Technologies in Púchov, Alexander Dubček University of Trenčín. I. Krasku 491/30, 02001 Púchov. Slovak Republic. E-mail: jan.krmela@tnuni.sk

${ }^{3}$ Faculty of Technical Systems and Energy Efficient Technologies, Sumy State University. Rymskogo-Korsakova st., 2, 40007, Sumy. Ukraine. E-mail: hovorun@pmtkm.sumdu.edu.ua, kr.berladir@pmtkm.sumdu.edu.ua ${ }_{4}^{4}$ Academic and Research Institute of Finance, Economics and Management, Sumy State University. RymskogoKorsakova st., 2, 40007, Sumy. Ukraine. E-mail: a.artyukhov@pohnp.sumdu.edu.ua

The design features of diaphragm compressors are discussed in this article. For preventing the formation of local stresses in certain areas of the diaphragm, it is recommended to use thin sheet stainless steel of the transition class. A comparative analysis is made of two batches of steel tape, differing in the value of the saturation magnetic induction, which is identical to the content of the martensite phase in the structure of the material before the final cycle of cold plastic deformation. The results of the study of the influence of the deformation temperature $\left(20-300{ }^{\circ} \mathrm{C}\right)$ on the change in mechanical properties $\left(\sigma_{\mathrm{b}}\right.$, $\sigma_{0.2}, \delta$ ) revealed a different tendency to embrittlement of the material of the tapes for these batches. For increasing the operational reliability of the compressor's diaphragm elements, it is recommended to use a material, the structure of which contains a certain amount of work-hardened retained austenite. This makes it possible to undergo additional martensitic transformation under the action of peak loads in local areas and increases the structural strength of corrosion-resistant steel for the manufacture of a compressor diaphragm.

Keywords: Corrosion-resistant Steel, Martensitic Transformation, Residual Austenite, Mechanical Properties, Cold Plastic Deformation

\section{Introduction}

A compressor is an energy machine or device for increasing pressure (compression) and moving gaseous substances. An air compressor is a unit whose operation principle is based on air compression with its subsequent transmission under pressure [1]. Compressor machines' application is vast: gas and oil, transport, energy, food processing, construction, automotive, medicine, and pharmaceuticals [2, 3].

The use of compressor equipment (as an additional one from the point of view of the technological process, but the main one from the point of view of the movement of gas streams) in devices for obtaining granular products and drying complexes is a prerequisite for their successful functioning. Providing various degrees of compression of the gas flow in the compressor equipment allows, for example, the dispersion of liquids (granulation equipment) $[4,5]$, the supply of a drying agent to the working space of the apparatus (drying and granulation devices [6]), the supply of a cooling agent to ensure the required temperature characteristics of the finished product before transporta- tion to the warehouse (drying and granulation devices). For specific industries (for example, porous ammonium nitrate), it is important to use pneumatic spraying at the humidification stage [7, 8], as well as in dust collection technology [9].

The choice of the type of compressor and the main structural materials are made based on the analysis of the technological process of chemical production (the required degree of compression of the medium, the temperature regime of the installation, the aggressiveness of the medium, the physicochemical properties of the medium, in particular, the presence of mechanical inclusions and/or liquid phase, etc.).

The diaphragm type air compressor has the following parameters:

- tightness;

- resistance to corrosion;

- high compression level;

- reliable design;

- safety in operation and ease of maintenance.

A diaphragm compressor is a positive displacement machine (Fig. 1) and, in terms of characteristics 
and principle of operation, is in many ways like a piston compressor [10]. Compression of gas in such a compressor occurs using a flexible diaphragm that reciprocates [11].

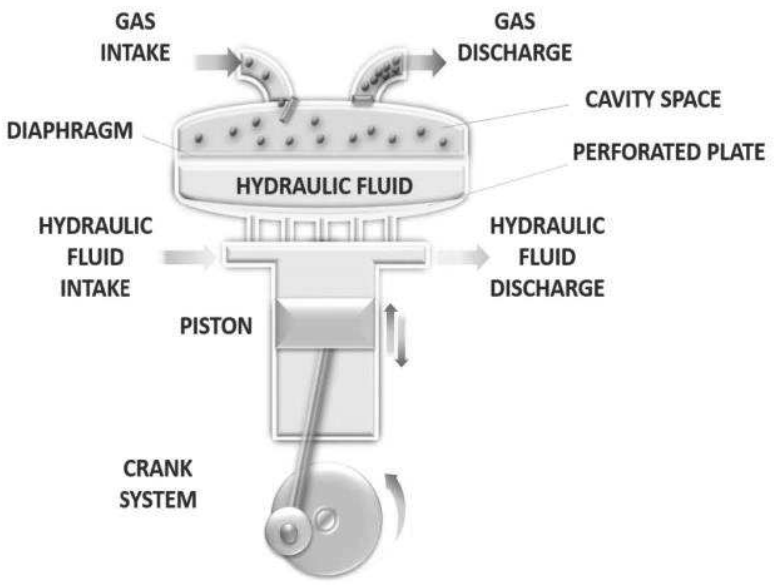

Fig. 1 Scheme of a metal diaphragm compressor [12]

One of the main structural elements of machines, ensuring their reliability, are elastic elements, which are made from various spring alloys. The role of elastic elements in compressor machines is performed by direct-flow valves and diaphragms, for the manufacture of which thin-sheet metal is used.

The diaphragm of a diaphragm compressor is an elastic element clamped around the periphery between the diaphragm block's distribution and restricting discs. A diaphragm divides the block cavity into two, communicating through self-acting valves with gas communications and the other with a hydraulic cylinder [12].

During the hydraulic drive operation, the diaphragm is imparted with an oscillatory movement, during which it must be tightly pressed against the profiled surface of the limiting disc. Depending on the design, the ratio of the diaphragm's deflection towards the distribution and limiting discs can be different, which characterizes the stress cycle. In general, this cycle is asymmetric. Thus, during operation, the diaphragm is subjected to cyclic alternating loads [11].

Simultaneously, from the point of view of the cycle of voltage change and the type of stress state, the most dangerous are the central and pinched diaphragm. Also, when the diaphragm moves along the profiled surface, the material undergoes contact corrosion and erosion due to the high velocity of the compressed gas in the area of the self-acting valve holes [13]. The effect of stress is aggravated by the fact that the compressed gas's temperature acts on the diaphragm material, which is $100-150^{\circ} \mathrm{C}$.

One of the features of the diaphragm operation is the formation of local stresses and their concentration in individual zones, which requires high resistance to the occurrence and development of cracks from the used thin-sheet materials [14].

Considering the above, the requirements for the material of the compressor diaphragm should include reliability, strength, resistance to multiple cycles, chemical resistance to the pumped medium.

Both carbon and stainless steel are used as thin sheet material [15]. High-strength stainless steels with the necessary set of properties have found the widest application [16]. These are transitional stainless steels, in the structure of which, after a cycle of deformationthermal action (rolling + aging), there is a certain amount of retained austenite [17], which can undergo a $\gamma \rightarrow \alpha$ transformation during operation [18]. The stability of retained austenite to martensitic transformation will determine the resistance of martensite to the centers of initiation and propagation of cracks [19], that is, to the intensity of destruction of the material under the action of operating factors [20,21].

Thus, for the effective use of high-strength stainless steels under the operating conditions of the elastic elements of diaphragm compressors, the scientific interest is studying the influence of the technology of manufacturing a steel tape on the change in the physical and mechanical properties of the material used.

\section{Methodology for obtaining samples and equipment for research}

According to the goal of this paper, two experimental batches of stainless maraging steel tape were made. The chemical composition of this steel is presented in Table 1.

Tab. 1 The chemical composition of corrosion-resistant steel of austenitic-martensitic class, \% by weight

\begin{tabular}{|c|c|c|c|c|c|c|c|c|}
\hline $\mathrm{C}$ & $\mathrm{Si}$ & $\mathrm{Mn}$ & $\mathrm{Cr}$ & $\mathrm{Ni}$ & $\mathrm{Al}$ & $\mathrm{S}$ & $\mathrm{P}$ & $\mathrm{Fe}$ \\
\hline up to 0.09 & up to 0.8 & up to 0.8 & $14.0-16.0$ & $7.0-9.4$ & $0.7-1.3$ & up to 0.025 & up to 0.035 & $\sim 74.0$ \\
\hline
\end{tabular}

The analysis of changes in the structure and properties of an investigated material with different modes of continuous rolling to obtain rolled stock and subsequent deformation at elevated temperatures was carried out by thermal microscopy using an IMASH-2075 high-temperature test setup. The samples were heated by the convective method with temperature recording by a contact thermocouple in the range of 20
$-300{ }^{\circ} \mathrm{C}$. Cyclic strength tests were carried out with a base $N=5 \cdot 10^{6}$ cycles. The study of changes in the fine crystal structure of austenite was carried out in chromium radiation. The results of changes in the dependence of physical and mechanical properties under continuous cold plastic deformation (CPD) are shown in Table 2. 
Tab. 2 Change in the physical and mechanical properties of steel during continuous CPD

\begin{tabular}{|c|c|c|c|c|c|c|c|c|c|c|}
\hline \multirow{2}{*}{$\begin{array}{l}\text { Designa- } \\
\text { tion of the } \\
\text { batches }\end{array}$} & \multirow{2}{*}{$\begin{array}{l}\text { Thic- } \\
\text { kness af- } \\
\text { ter } \\
\text { rolling }\end{array}$} & \multirow{2}{*}{$\begin{array}{l}\text { Num- } \\
\text { ber of } \\
\text { passes }\end{array}$} & \multicolumn{2}{|c|}{$\begin{array}{l}\text { Total re- } \\
\text { duction }\end{array}$} & \multicolumn{6}{|c|}{ Physical and mechanical properties } \\
\hline & & & $\mathrm{mm}$ & $\%$ & $\begin{array}{c}\overline{\mathbf{B}}_{\max }, \\
\mathrm{G}\end{array}$ & $\begin{array}{l}\mathrm{H}_{\mu,} \\
\mathrm{MPa}\end{array}$ & $\begin{array}{l}\sigma_{0,2}, \\
\mathrm{MPa}\end{array}$ & $\begin{array}{l}\sigma_{\mathrm{b}} \\
\mathrm{MPa}\end{array}$ & $\delta, \%$ & $\begin{array}{c}\sigma_{-1}, \\
\mathrm{MPa}\end{array}$ \\
\hline SM & 0.65 & - & - & 0 & 554 & 1490 & 220 & 920 & 14.0 & 305 \\
\hline SM-1 & 0.50 & 1 & 0.15 & 23 & 1892 & 3060 & 560 & 950 & 8.5 & 500 \\
\hline SM-2 & 0.45 & 2 & 0.20 & 31 & 4804 & 3830 & 770 & 1180 & 8.5 & 650 \\
\hline SM-3 & 0.39 & 3 & 0.26 & 40 & 6745 & 4090 & 950 & 1150 & 7.0 & 720 \\
\hline $\mathrm{S}$ & 0.76 & - & - & 0 & 1245 & 1710 & 340 & 1000 & 11.0 & 315 \\
\hline S-1 & 0.63 & 1 & 0.13 & 17 & 2937 & 3170 & 450 & 1150 & 9.0 & 370 \\
\hline $\mathrm{S}-2$ & 0.50 & 2 & 0.26 & 34 & 5725 & 3760 & 940 & 1420 & 9.0 & 510 \\
\hline S-3 & 0.42 & 3 & 0.34 & 44 & 7549 & 4120 & 1210 & 1440 & 7.5 & 550 \\
\hline S-4 & 0.38 & 4 & 0.38 & 50 & 8969 & 4350 & 1270 & 1400 & 5.8 & 650 \\
\hline
\end{tabular}

The studies were carried out for two batches of tape ( $(S)$ and $\langle\mathrm{SM} »)$, differing in the value of the saturation magnetic induction, which is identical to the content of the martensite phase in the structure of the material before the final CPD cycle. One of the batches («S») was rolled with a total reduction rate of $50 \%$ in four passes, and the second ( $\langle\mathrm{SM}\rangle)$ - with a total reduction rate of $40 \%$ in three passes.

\section{Experimental results and their discussion}

The change in the characteristics of the fine structure of retained austenite is shown in Fig. 2.

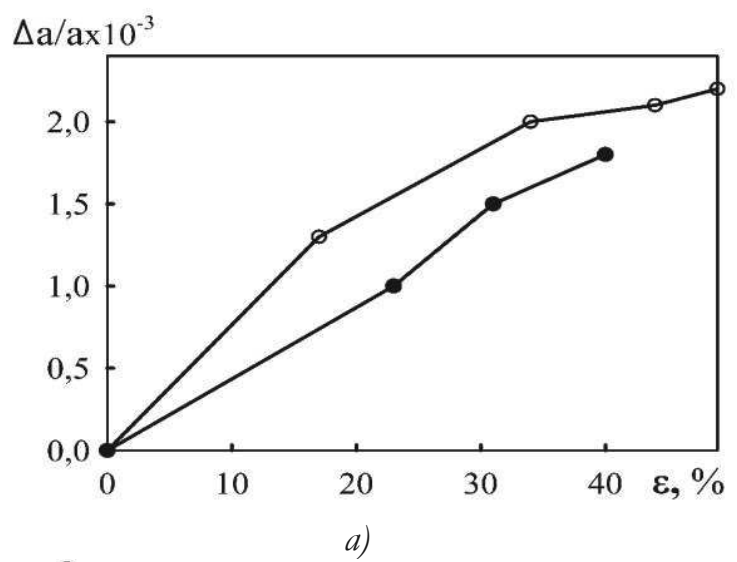

Dr, $\stackrel{\AA}{\AA}$

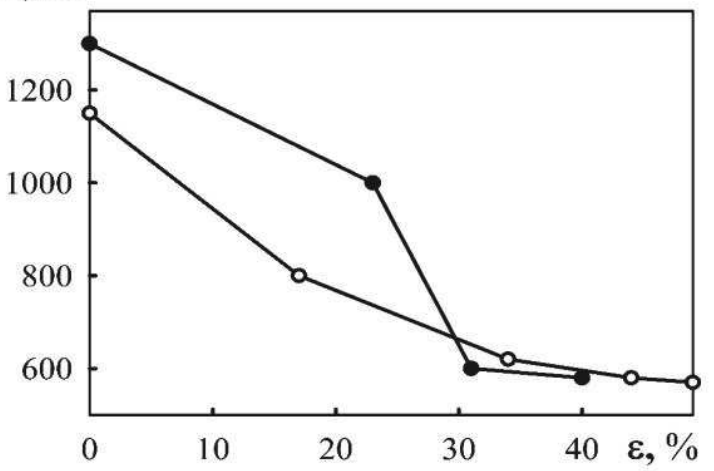

b)

Fig. 2 Dependence of the magnitude of microstresses $\Delta a / a(a)$ and the size of blocks $D \gamma$ of the $\gamma$-phase (b) for batches " $S$ 》

(O) and « $S M »(\bullet)$
An analysis of the graphical dependence of the magnitude of microstresses $(\Delta a / a)$, size of blocks $\left(D_{\gamma}\right)$, microhardness $\left(H_{\mu}\right)$ and saturation magnetic induction (b) shows that with an increase in the degree of plastic deformation $(\varepsilon)$, the hardness, the magnitude of microstresses and hardness with different intensity for batches with saturation magnetic induction of $554 \mathrm{G}$ $(« S M »)$ and $1245 \mathrm{G}(« S »)$. The size of the coherent scattering regions is reduced by three times.

An analysis of the change in properties (Table 2) shows that for a batch with a saturation magnetic induction of $1245 \mathrm{G}$ before the CPD process during rolling, a more significant increase in the yield stress and hardness values is observed.

At the same time, the fatigue limit of samples from a finished tape of a given batch is lower than for a batch with a lower value of the saturation magnetic induction before CPD $\left(\overline{\boldsymbol{B}}_{\max }=554 \mathrm{G}\right)$. This phenomenon may be because for transitional steels during fatigue tests, the process of additional transformation of retained austenite is possible.

Figures 3 and 4 show the graphs of changes in mechanical properties $\left(\sigma_{b}, \sigma_{0.2}, \delta\right)$ depending on the deformation temperature in the temperature range of $20-$ $300^{\circ} \mathrm{C}$.

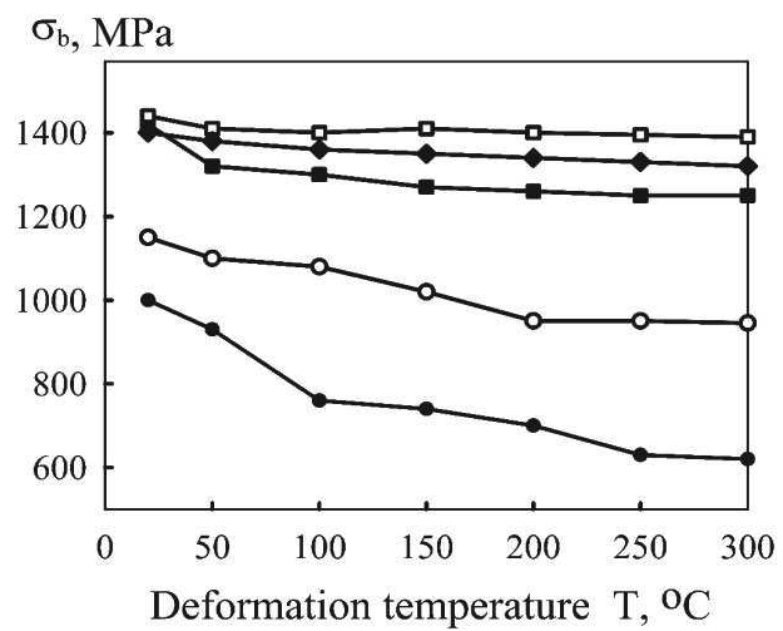

a) 


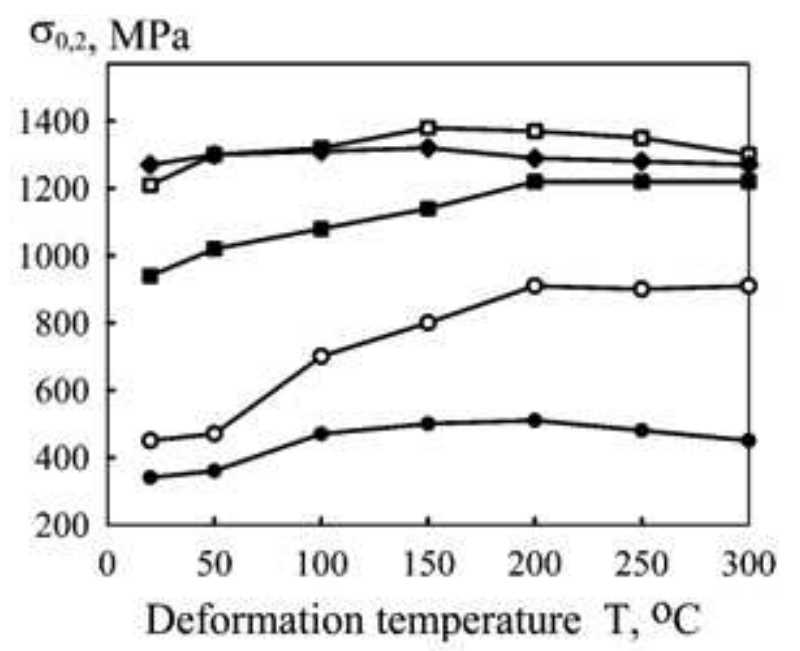

b)

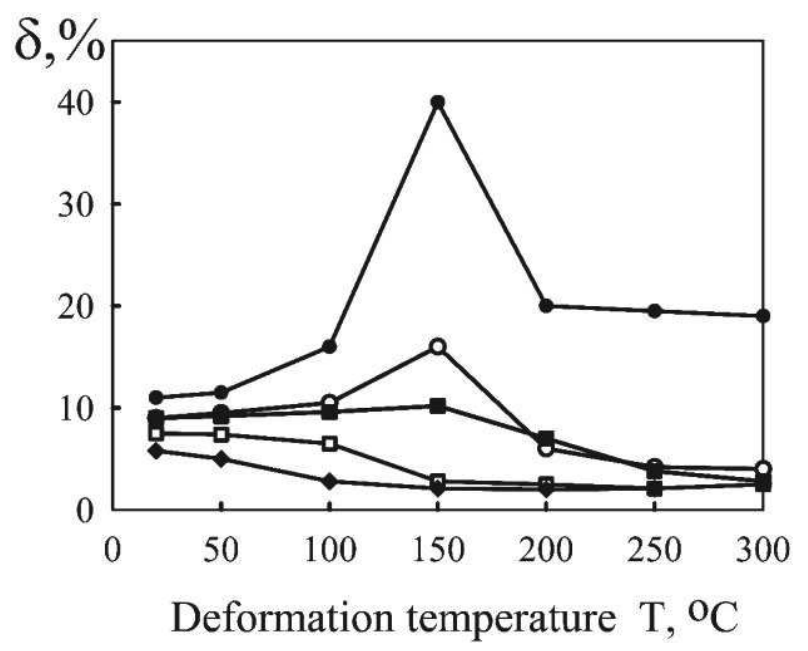

c)

Fig. 3 Change in the temperature dependence of the properties of the batch $\langle S\rangle: a-\sigma_{b} ; b-\sigma_{0,2} ; c-\delta ; \bullet-S ; \circ-S-1$;

$$
S-2 ; \square-S-3 ;-S-4
$$

Depending on the percentage and fine structure of retained austenite (microstresses, dislocation density, and sizes of coherent scattering regions), the transformation will occur with different intensities at equal maximum cycle stresses.

With an increase in the degree of deformation, the character of hardening for an investigated batches changes in the same way. At the same time, the change in the size of blocks and microstresses, determined by the X-ray method from the width of the lines, allows us to conclude that a larger amount of the martensite phase in the structure of the tape material before plastic deformation promotes a more intense work-hardening of retained austenite during rolling, as well as a greater distortion of the crystal lattices of the structural components. Studies of the effect of the deformation temperature on the change in mechanical properties made it possible to reveal a different tendency to embrittlement of the tapes' material for these batches.

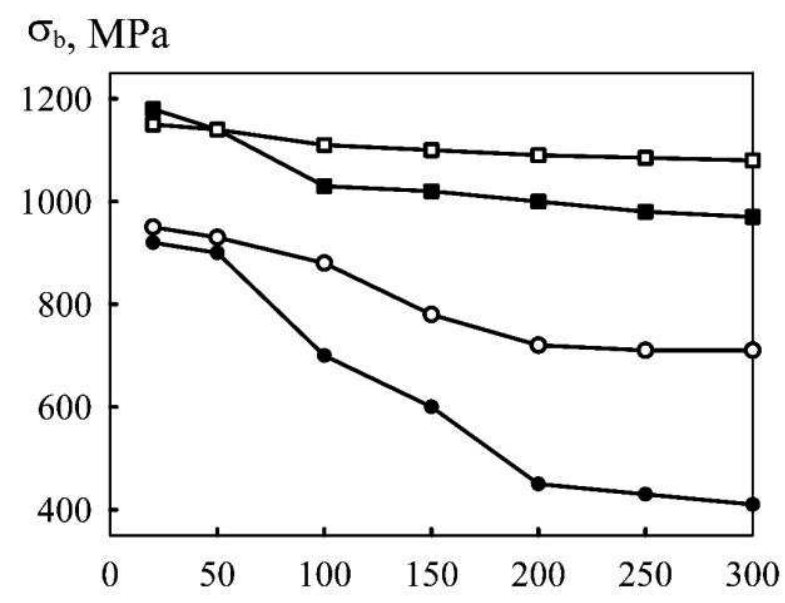

Deformation temperature $\mathrm{T},{ }^{\circ} \mathrm{C}$ a)

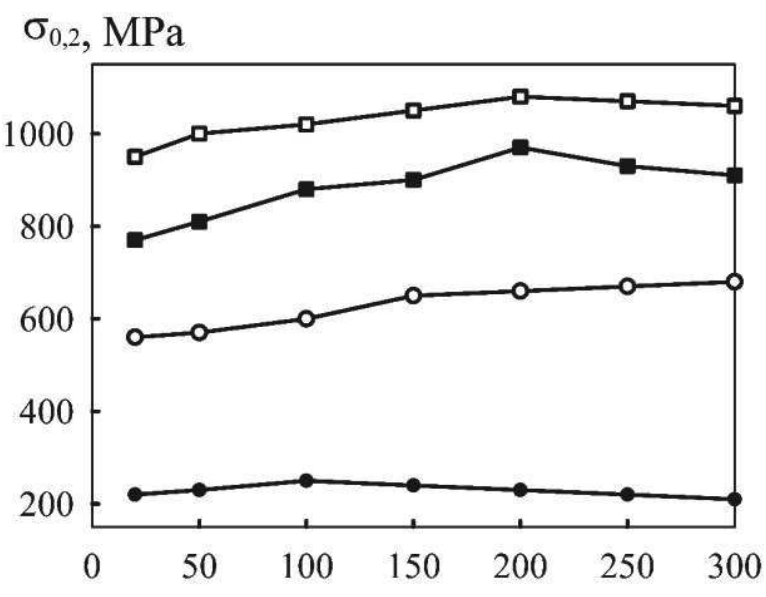

Deformation temperature $\mathrm{T},{ }^{\circ} \mathrm{C}$ b)

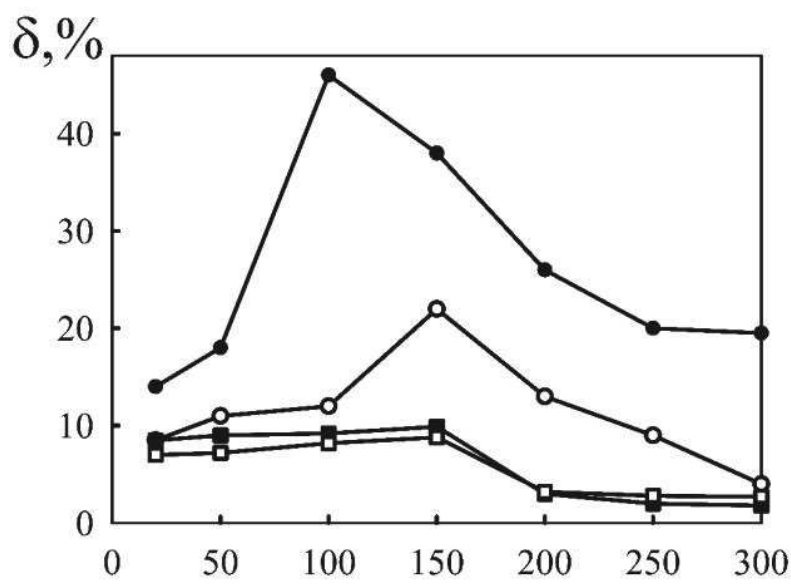

Deformation temperature $\mathrm{T},{ }^{\mathrm{o}} \mathrm{C}$ c)

Fig. 4 Change in the temperature dependence of the properties of the batch $\langle S M\rangle: a-\sigma_{b} ; b-\sigma_{0,2} ; c-\delta ; \bullet-S M ; \circ-$ $S M-1 ; \square-S M-2 ; \square-S M-3$ 
If we compare the graphs of changes in mechanical properties (Fig. 2), it can be seen that the material of the rolled stock of batch «S» already has a tendency to deformation aging and the yield strength increases from 340 to $520 \mathrm{MPa}$ at a deformation temperature of 20 and $200{ }^{\circ} \mathrm{C}$ respectively. For the batch «SM» (initial state), the yield stress of the rolled stock practically does not change in the entire investigated range of deformation temperatures.

The change in the relative elongation is characterized by the presence of a maximum, while its absolute values are higher for the batch, the structure of which contains a smaller amount of martensite ( $(\mathrm{S} M »)$.

Cold plastic deformation already at the first passes of the tape leads to an increase in the yield stress values, magnetic induction of saturation, and distortion of the crystal lattices of martensite and retained austenite. With an increase in the deformation temperature during subsequent tests, it can be noted that for samples «S-1» the yield strength increases more intensively (Figs. 3, 4) than for samples «SM-1».

The character of the change in the relative elongation has a dependence like the samples «S» and «SM», but the quantitative values of plasticity have significantly decreased. Further cold plastic deformation of steel by $31 \%(\mathrm{SM}-2)$ and $34 \%$ (S-2) leads to the achievement of the maximum values of the yield stress and minimum values of plasticity in the region of lower deformation temperatures during subsequent tests. Since the rate of strain aging is largely determined by the diffusion mobility of impurity atoms, it can be assumed that under these rolling modes, not only the formation of deformation martensite occurs with an inheritance of defects in the crystal structure of austenite, but also intense distortions of the crystal lattice of the existing martensite with an increase in the density of dislocations and fragmentation of blocks. The rolling of steel with an even greater total degree of deformation leads to further distortion of the crystal lattice of martensite and, consequently, a greater degree of strain aging manifestation. For example, for batch «S-4», the embrittlement effect appears already at a deformation temperature of $100^{\circ} \mathrm{C}$.

The different character of the change in the relative elongation with an increase in the test temperature for batches subjected to small and large (over $40 \%$ ) degrees of total deformation should also be noted. This is clearly manifested in a decrease in the maximum curve of the temperature dependence of the relative elongation for the batch SM-1, SM-2, SM-3, S-1, S-2 and in its absence for the batches S-3 and S-4.

Thus, the revealed tendency to change the relative elongation and yield strength of steel with an increase in the deformation temperature during testing allow us to assume that dynamic deformation aging of this steel at operating temperatures of the diaphragms of the elastic elements of diaphragm compressor machines is associated with the presence of deformation martensite and residual austenite in the material structure. In this case, the critical degree of deformation during rolling is $\sim 35 \%$, after which an intense distortion of the crystal lattice of retained austenite and martensite occurs, leading to the manifestation of deformation aging of the steel at deformation temperatures of less than $100{ }^{\circ} \mathrm{C}$. Simultaneously, the more thermal martensite is contained in the rolled stock material before $\mathrm{CPD}$, the lower the test temperature the embrittlement effect appears.

The study of the dependence of the analyzed steel's mechanical properties after different processing modes (CPD + aging) shows that an increase in the aging temperature shifts the temperature range of embrittlement to the region of higher temperatures. Comparing the results of fatigue tests and the temperature dependence of the relative elongation at $150^{\circ} \mathrm{C}$ shows (Fig. 5) that the optimal aging temperature is heating at $520^{\circ} \mathrm{C}$.

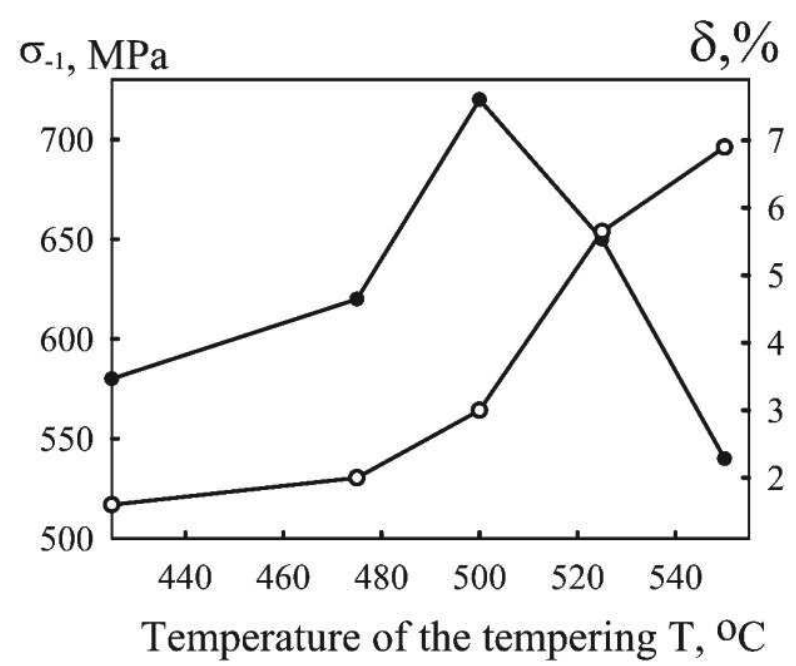

Fig. 5 The effect of aging temperature on the change in the cyclic strength of corrosion-resistant steel: $\bullet-\sigma_{-1} ; \bigcirc-\delta$

The method of obtaining martensite in the structure of steel also significantly affects the kinetics of changes in material properties.

\section{Conclusion}

1. The complex studies carried out made it possible to determine the modes of manufacturing a coldrolled high-strength stainless steel tape, considering the change in properties during deformation at elevated temperatures. The results of the comparative analysis on the effect of operating conditions on the change in physical and mechanical properties allow us to conclude that the material of the diaphragms is characterized by an intense course of dynamic deformation aging processes, which manifest themselves in an increase in the resistance to initial plastic deformation and a sharp decrease in the characteristics of 
general plasticity, thereby reducing the resistance of the material to fracture processes.

2. It was revealed that the critical degree of deformation during rolling is about $35 \%$. An intense distortion of the crystal lattice of retained austenite and martensite occurs, leading to the manifestation of deformation aging of steel at deformation temperatures of less than $100{ }^{\circ} \mathrm{C}$. The more thermal martensite is contained in the rolled stock material before CPD, the lower the test temperature is embrittlement. It compared the results of fatigue tests, and the temperature dependence of the relative elongation at $150^{\circ} \mathrm{C}$ shows that the optimal aging temperature is heating at 520 ${ }^{\circ} \mathrm{C}$.

3. The change in the size of the blocks and microstresses, determined by the X-ray method from the width of the lines, allows us to conclude that a larger amount of the martensite phase in the structure of the tape material before plastic deformation promotes a more intense work-hardening of retained austenite during rolling, as well as a greater distortion of the crystal lattices of the structural components.

4. For increasing the operational reliability of diaphragms (elastic elements of compressor machines), it is recommended to produce a steel tape containing a certain amount of work-hardened retained austenite in the structure with characteristics $\sigma_{0.2} / \sigma_{b}=0.7$. This contributes to undergoing a martensitic transformation under the action of peak loads in local areas.

5. Experimental batches of diaphragms were made from the steel tape that passed the research and sent to the industrial testing enterprise.

\section{Acknowledgments}

This research work had been supported by the Cultural and Educational Grant Agency of the Slovak Republic (KEGA), project No. KEGA 002TnUAD-4/2019 and by the Ministry of Science and Education of Ukraine under the project „Small-scale energy-saving modules with the use of multifunctional devices with intensive hydrodynamics for the production, modification and encapsulation of granules", project No. $0119 U 100834$.

\section{References}

[1] YUEHUA, LI, PUCHENG, PEI, ZE, MA, PENG, REN, HAO, HUANG (2020). Analysis of air compression, progress of compressor and control for optimal energy efficiency in proton exchange membrane fuel cell. In: Renewable and Sustainable Energy Reviews. Vol. 133, pp. 110304. ISSN 1364-0321. DOI: 10.1016/j.rser.2020.110304
[2] GOVORUN, T. P., LYUBICH, A. I. (2016). Surfacing Layer Development for Cast Iron Object Repair. In: Chemical and Petroleum Engineering. Vol. 52, No. 7 - 8, pp. 502 - 505. DOI: 10.1007/s10556-016-0222-5

[3] GOVORUN, T. P., LYUBICH, A. I. (2017). Theoretical description of the formation of nodular graphite deposited metal for compressor components. In: Welding international. Vol. 31, No. 5, pp. 374 - 379. DOI: 10.1080/09507116.2016.1263460

[4] ARTYUKHOV, A., ARTYUKHOVA, N., IVANIIA, A., GALENIN, R. (2017). Progressive equipment for generation of the porous ammonium nitrate with 3D nanostructure. In: Proceedings of the 2017 IEEE 7 th International Conference on Nanomaterials: Applications and Properties (NAP 2017), pp. 03NE06-1 - 03NE06-4.

[5] ARTYUKHOV, A. E., ARTYUKHOVA, N. O. (2019). Technology and the main technological equipment of the process to obtain $\mathrm{N}_{4} \mathrm{HNO}_{3}$ with Nanoporous Structure. In: Springer Proceedings in Physics. Vol. 221, pp. 585 594.

[6] KRMELA, J, ARTYUKHOVA, N, ARTYUKHOV, A. (2020). Investigation of the Convection Drying Process in a Multistage Apparatus with a Differential Thermal Regime. In: Manufacturing Technology. Vol. 20, No. 4, pp. 468 - 473. DOI: $10.21062 / \mathrm{mft} .2020 .062$.

[7] ARTYUKHOVA, N. O., KRMELA, J. (2019). Nanoporous structure of the ammonium nitrate granules at the final drying: The effect of the dryer operation mode. In: Journal of Nanoand Electronic Physics. Vol 11, No. 4, pp. 04006.

[8] ARTYUKHOVA, N. O. (2020). Morphological features of the nanoporous structure in the ammonium nitrate granules at the final drying stage in multistage devices. In: Journal of Nanoand Electronic Physics. Vol. 12, No. 4, pp. 04036.

[9] ARTYUKHOVA, N. A., ARTYUKHOV, A. E. (2018). Utilization of dust and ammonia from exhaust gases: new solutions for dryers with different types of fluidized bed. In: Journal of Environmental Health Science and Engineering. Vol. 16, No. 2, pp. 1 - 12.

[10] ZOU, J., HAN, N., YAN, J. et al. (2020). Electrochemical Compression Technologies for High-Pressure Hydrogen: Current Status, Challenges and Perspective. In: Electrochem. Energ. Rev. Vol. 3, pp. 690 - 729. DOI: 10.1007/s41918-020-00077-0 
[11] DEHNEN, M. (1995). Chapter Eleven - Diaphragm compressors. In: Editor(s): Gerhard Vetter, Leak-Free Pumps and Compressors Handbook, Elsevier Science. pp. 231 - 249. ISBN 9781856172301. DOI: 10.1016/B978185617230-1/50011-0.

[12] SDANGHI, G., MARANZANA, G., CELZARD, A., FIERRO, V. (2019). Review of the current technologies and performances of hydrogen compression for stationary and automotive applications. In: Renewable and Sustainable Energy Reviews. Vol. 102, pp. 150 - 170. ISSN 1364-0321. DOI: 10.1016/j.rser.2018.11.028

[13] XIAOHAN, JIA, JIAHAO, CHEN, HAN, WU, XUEYUAN, PENG (2016). Study on the diaphragm fracture in a diaphragm compressor for a hydrogen refueling station. In: International Journal of Hydrogen Energy. Vol. 41, No. 15, pp. 6412 - 6421. ISSN 0360-3199. DOI: 10.1016/j.ijhydene.2016.02.106

[14] YUANLIN, HU, XIAOYING, XU, WEN, WANG (2017). A new cavity profile for a diaphragm compressor used in hydrogen fueling stations. In: International Journal of Hydrogen Energy. Vol. 42, No. 38, pp. 24458 - 24469. ISSN 0360-3199. DOI: 10.1016/j.ijhydene.2017.08.058

[15] CAMERON, J. A., DANOWSKI, F. M. (1973). Some Metallurgical Considerations in Centrifugal Compressors. Texas A\&M University. Gas Turbine Laboratories.

[16] DOWSON, P., BAUER, D., LANEY, S. (2008). Selection of Materials and Material Related Processes for Centrifugal Compressors and Steam Turbines in the Oil and Petrochemical Industry. Texas
A\&M University. Turbomachinery Laboratories.

[17] KUČEROVÁ L, JANDOVÁ, A, RUBEŠOVÁ, K. (2019). Microstructure Analysis and Mechanical Properties of Low Alloyed Steel with Retained Austenite Obtained by Heat Treatment. In: Manufacturing Technology. Vol. 19. No. 2, pp. 243 - 247. DOI: 10.21062/ujep/277.2019/a/12132489/MT/19/2/243

[18] SOMANI, M. C., KARJALAINEN, L. P., OLDENBURG, M., ERIKSSON, M. (2001). Effects of plastic deformation and stresses on dilatation during the martensitic transformation in a B-bearing steel. In: J Mater Sci Technol. Vol. 17, No. 02, pp. $203-206$.

[19] BUNDA, Z, KUČEROVÁ, L, KEPKA M. (2019). The Crack Analysis of Fatigue Tested Steel Construction. In: Manufacturing Technology. Vol. 19, No. 4, pp. 559 - 562. DOI: $10.21062 /$ ujep/334.2019/a/12132489/MT/19/4/559

[20] JÄRVENPÄÄ, A., JASKARI, M., KISKO, A., KARJALAINEN, P. (2020). Processing and Properties of Reversion-Treated Austenitic Stainless Steels. In: Metals. Vol. 10, No. 2, pp. 281. DOI: $10.3390 / \operatorname{met} 10020281$

[21] ZHANG, L., ANA, B., IIJIMA, T., FUKUYAMA, S., YOKOGAWA, K. (2011). Anomalous plastic deformation and martensitic transformation in metastable austenitic steels at low strain rate characterized by in-situ hydrogen and argon releases and scanning probe microscopy. In: Journal of Applied Physics. Vol. 110, pp. 033540. DOI: 10.1063/1.3622516 